\title{
Erratum
}

Zai-Qiu Wang, Xiao-Li Sun, Jin-Liang Li

\section{Erratum to "MYL6B drives the capabilities of proliferation, invasion, and migration in rectal adenocarcinoma through the EMT process"}

https://doi.org/10.1515/biol-2020-0103

received October 16, 2020; accepted October 16, 2020

In the published article "Li J-L, Wang Z-Q, Sun X-L. MYL6B drives the capabilities of proliferation, invasion, and migration in rectal adenocarcinoma through the EMT process. Open Life Sci. 2020;15:522-31. doi: 10.1515/biol2020-0031" the order of authors is incorrect.

The correct order of authors is as follows: Zai-Qiu Wang ${ }^{\#}$, Xiao-Li Sun ${ }^{\#}$, Jin-Liang Li ${ }^{\star}$

\# These authors contributed equally to this work

* Corresponding author 